\title{
APLICAÇÃO DE BENTONITA EM UM REGOSSOLO EUTRÓFICO I. EFEITOS SOBRE AS PROPRIEDADES FÍSICO-HÍDRICAS DO SOLO'
}

\author{
Gilvanise Alves 'Tito ${ }^{2}$, Lúcia Helena Garófalo Chaves ${ }^{3}$, Hugo Orlando Carvallo ${ }^{3}$ \\ e Norma César Azevedo
}

\section{RESUMO}

O trabalho foi desenvolvido no período de 1995 a 1996, no Laboratório de Irrigação e Salinidade do Departamento de Engenharia Agrícola/CCT/UFPB. Os efeitos da aplicação de bentonita Primavera, nas propriedades físico- hídricas do solo foram avaliados em amostras de um regossolo eutrófico. As amostras de solo foram coletadas a uma profundidade de $0-20 \mathrm{~cm}$ e incubadas por 120 dias com doses de bentonita equivalentes a $0,30,60 \mathrm{e} 90 \mathrm{t} \mathrm{ha}^{-1}$. Após esse período, determinou-se a condutividade hidráulica nas amostras de terra e, em seguida, suas características físico-hídricas. A retenção de água pelo solo aumentou com as doses de bentonita. Quando comparadas com a testemunha, a disponibilidade de água para as planlas aumentou enquanto a condulividade hidráulica diminuiu em função das doses de bentonita aplicadas ao solo.

Palavras chave: bentonila, regossolo eutrófico, retenção de água, água disponível, condutividade hidráulica, propriedades físico-hídricas

\section{APPLICATION OF BENTONITE IN A EUTROPHIC RHEGOSOL I.EFFECTS ON THE SOIL PHYSICO-HYDRICAL PROPERTIES}

\begin{abstract}
This study was carried out from 1995 to 1996, at the Laboratory of Irrigation and Salinity of of the Department of Agricultural Engineering of CCT/UFPB. The effects of the application of Primavera bentonite, on the soil physico-hydrical properties, were evaluated in samples of a eutrophic rhegosol. Such samples of soil from 0 to $20 \mathrm{~cm}$ depth were incubated for 120 days with doses of bentonite equivalent to 0,30,60 and $90 \mathrm{tha}{ }^{1}$. After this time, the hydraulic condutivity of the soil and their physico-hydrical properties were determined. The soil water retention increased with the bentonite doses. When compared with the control the available water for plants increased with the bentonite application. The hydraulic condutivity decresead in relation to the control.
\end{abstract}

Key words: bentonite, eutrophic rhegosol, soil water retention, available water for the plants, hydraulic conductivity, physico-hydrical properties

\section{INTRODUÇÃO}

Atualmente, a preocupação por parte de vários segmentos da sociedade em conter os desequilibrios ecológicos provocados pelo descarte de resíduos urbanos e industriais, tem levado ao desenvolvimento de pesquisas no sentido de se buscar soluções para a utilização econômica desses resíduos. Neste contexto, tem sido investigada a possibilidade do uso agronômico como material condicionador de solo ou mesmo como fertilizante, de diferentes tipos de resíduos como o composto de lixo urbano,

\footnotetext{
${ }^{1}$ Parle da Dissertaç̃o de Mestrado do primeiro autor apresentada no Centro de Ciências e Tecnologia da Universidade Federal da Paraiba. Campina Grande, PB.

${ }^{2}$ Engenheiro Agrícola . Rua Antonio Catão 560, Campina Grande, PB.

3 Professores Titulares do Departamento de Engenharia Agrícola do Centro de Ciências e Tecnologia da Universidade Federal da Paraíba. Campina Grande, PB.

${ }^{4}$ Professor Adjunto do Depto. de Engenharia Agrícola do Centro de Ciências e Tecnologia da Universidade Federal da Paraíba. Campina Grande, PB.
} 
lodo de esgoto, resíduo de bauxita, cinza de caldeira, pó de basalto, lodo da indústria de celulose e papel, e outros (Messias \& Morais, 1992; Logan \& Prezollo, 1992; Ros et al., 1993; Fortes \& Campos Neto, 1995; Novelino et al., 1995; Souza et al., 1996). Da mesma forma, têm sido pesquisados, como condicionadores de solo, apesar de não serem resíduos, o betume e a vermiculita expandida (Salati et al, 1980; Choudhury \& Faria, 1982).

A bentonita, encontrada em grandes quantidades em depósitos no município de Boa Vista, PB ,é um argilo-mineral constituído por misturas de nontronita ou nontronita-beidelita, por ilita, caulinita, por camadas mistas ilita-montmorilonita e por pequenos teores de quartzo. Seu teor ponderal de argilomineral montmorilonítico varia entre 55 a $70 \%$. Conforme suas caracterísiticas físicas e químicas, é ulilizada ou não na indústria de diferentes produtos. Aquela que não satisfaz às exigências necessárias para a indústria, denominada regionalmente "bofe" , tem sido rejeitada e acumulada em grandes montanhas a céu aberto na região, causando problemas ambientais. Este rejeito, devido à sua natureza mineralógica, apresenta alta capacidade de retenção de água (Santos, 1976).

O regossolo eutrófico é um solo arenoso que apresenta baixa capacidade de retenção de água, no entanto, a microrregião do Brejo Paraibano tem regossolos de alta significancia agrícola. Considerando-se os problemas atuais do meio ambiente, as limitações dos regossolos e a tentativa de se encontrar alternativas de uso para o material "bofe", este trabalho foi desenvolvido com o objetivo de se estudar os efeitos da aplicação de bentonita sobre as propriedades lísico-hídricas de um regossolo eutrófico.

\section{MATERIAL E MÉTODOS}

O trabalho foi desenvolvido em casa de vegetação pertencente ao Laboratório de Irrigação e Salinidade do Departamento de Engenharia Agrícola do Centro de Ciências e Tecnologia da Universidade Federal da Paraíba, em Campina Grande, PB , no período de 1995 a 1996. Foi utilizada uma amostra superficial de um regossolo eutrófico coletada na profundidade de 0 a $20 \mathrm{~cm}$, na microrregião de Esperança, Estado da Paraíba. Após ser homogeneizada, secada ao ar e passada em peneira de $2 \mathrm{~mm}$ de abertura, a amostra foi analisada com respeito às suas características lísico-hidricas (Tabela 1).

A bentonita utilizada, conhecida regionalmente por "bofe", foi coletada na jazida Primavera, no município de Boa Vista, PB. Após seca ao ar e passada em peneira de $2 \mathrm{~mm}$ de

Tabela 1. Características físicas do regossolo e da bentonita utilizada

\begin{tabular}{lcc}
\hline CARACTERISTICA & REGOSSOLOLO & BENTONITA \\
\hline Areia $\left(\mathrm{g} \mathrm{kg}^{-1}\right)$ & 841,60 & 9,20 \\
Silte $\left(\mathrm{g} \mathrm{kg}^{-1}\right)$ & 91,80 & 364,30 \\
Argila $\left(\mathrm{g} \mathrm{kg}^{1}\right)$ & 66,60 & 626,50 \\
Densidade Global $\left(\mathrm{kg} \mathrm{dm}^{3}\right)$ & 1,54 & 0,62 \\
Densid. das Partículas $\left(\mathrm{kg} \mathrm{dm}^{3}\right)$ & 2,65 & 2,20 \\
Supcrficie Especílica $\left(\mathrm{m}^{2} \mathrm{~g}^{1}\right)$ & & 312,17 \\
Capacidade de Campo $\left(\mathrm{m}^{3} \mathrm{~m}^{-3}\right)$ & 7,90 & \\
Ponto de Murcha Pcrmancnte $\left(\mathrm{m}^{3} \mathrm{~m}^{-3}\right)$ & 1,80 & \\
Classe Textural (USDA) & Areia liranca &
\end{tabular}

abertura, foi caracterizada também lísicamente (Tabela 1). Cada unidade experimental, constituída de $2 \mathrm{~kg}$ de terra, contida em vasos plásticos, misturada e homogeneizada com uma dose de bentonita, foi submetida a um período de incubação de 120 dias, ao longo do qual a umidade do solo foi mantida a $80 \%$ da capacidade de campo. As doses de bentonita utilizadas foram 0 , 30,60 e $90 \mathrm{t} \mathrm{ha}^{-1}$. A ausência de bentonita correspondeu à testemunha absoluta. Transcorridos 120 dias da instalação do experimento determinou-se, em cada unidade experimental, a condutividade hidráulica saturada, através de um permeâmetro de carga constante, conforme metodologia indicada por Reeve (1957); em seguida, retirou-se uma amostra de cada unidade experimental e determinaram-se as características fisico-hídricas do solo, incluindo as curvas de retenção de água, mediante o uso do extrator de Richards com placa de cerâmica, submetido às tensões de $10,13,33,43,101,3,506,5,1013,0$ e $1519,5 \mathrm{kPa}$ ( Richards , 1948). A água disponível para as plantas foi obtida a partir dessas curvas, através da diferença do conteúdos de água na capacidade de campo $(-10,13 \mathrm{kPa})$ e no ponto de murcha permanente $(-1519,5 \mathrm{kPa})$. Pelo método da pipeta determinouse a argila dispersa em água (EMBRAPA, 1979). O experimento foi desenvolvido em casa de vegetação, com um delineamento estatístico inteiramente casualizado, com três repetições por tratamento.

\section{RESULTADOS E DISCUSSÃO}

Na Tabela 2 são apresentados os valores médios da distribuição do tamanho das partículas e a classificação textural das amostras de solo determinados aos 120 dias da implantação do experimento, em função dos tratamentos.

Com exceção da testemunha, nos tratamentos em que se adicionou bentonita ao solo houve aumento do conteúdo de argila. Observa-se, inclusive, que o solo mudou de classe textural, passando de areia franca para franco-arenoso. Menor diferença foi encontrada entre os tratamentos em que foi aplicada a bentonita.

A retenção de água do solo aumentou com as doses de bentonita, como pode ser observado na Figura 1, que mostra a relação entre o conteúdo de água do solo e a tensão. Este aumento é decorrente, provavelmente, do aumento do teor de argila no solo, provocado pela adição da bentonita. Embora os conteúdos de argila dos solos submetidos aos tratamentos de 30, 60 e $90 \mathrm{t}$ ha ${ }^{1}$ não tenham sido muito diferentes entre si, a retenção de água no solo foi bem diferenciada, como pode ser observado na Figura 1.

Na Tabela 3 são apresentados os valores que indicam o efeito dos diferentes tratamentos utilizados, sobre a água disponível, condutividade hidráulica e argila dispersa no solo. Observa-se que a adição de bentonita ao solo produziu aumento significativo da água Tabela 2. Valores médios da distribuição do tamanho das partículas e classificação textural das amostras de solo determinados aos 120 dias após a implantação do experimento, em função dos tratamentos.

\begin{tabular}{ccccc}
\hline $\begin{array}{c}\text { Doses de bentonita } \\
\mathrm{t} \mathrm{ha}^{-1}\end{array}$ & $\begin{array}{c}\text { argila } \\
\mathrm{g} \mathrm{kg}^{-1}\end{array}$ & $\begin{array}{c}\text { silte } \\
\mathrm{g} \mathrm{kg}^{-1}\end{array}$ & $\begin{array}{c}\text { areia } \\
\mathrm{g} \mathrm{kg}^{-1}\end{array}$ & Classe textural \\
\hline 0 & 66,6 & 91,8 & 841,6 & areia franca \\
30 & 106,7 & 70,6 & 822,3 & franco arenoso \\
60 & 117,2 & 74,0 & 808,7 & franco arenoso \\
90 & 110,7 & 74,1 & 815,2 & franco arenoso \\
\hline
\end{tabular}




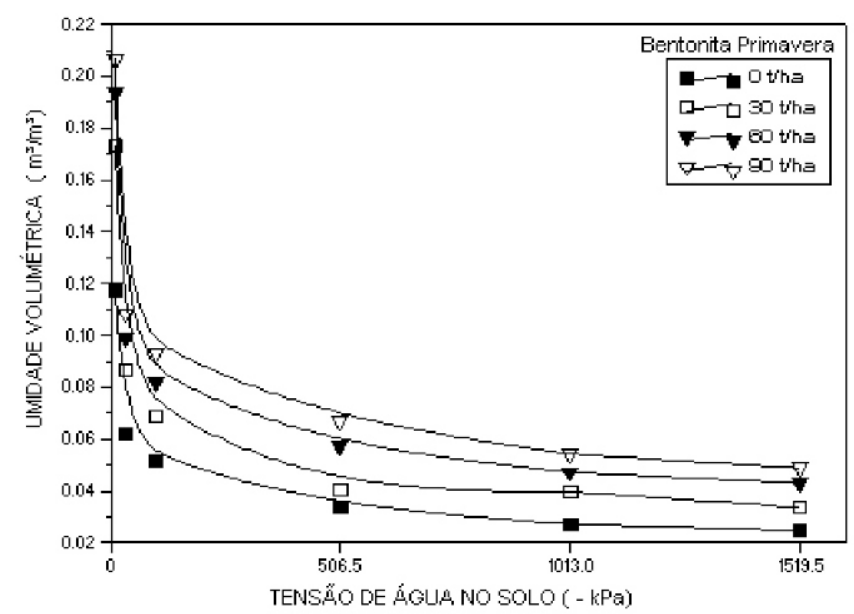

Figura 1. Curva de retenção de água do solo tratado com bentonita Primavera.

disponível para as plantas, quando comparado com a testemunha. Apesar das doses de bentonita terem aumentado a água disponível, este aumento foi significativo apenas em relação à testemunha, não havendo diferença entre os demais tratamentos. Em geral, esses acréscimos podem ler sido devidos às propriedades favoráveis à retenção de água que as bentonitas apresentam, por serem argilas constituídas por misturas montmorilonílicas e/ou argilo-minerais mistos de ilitamontmorilonita (Santos, 1975).

Comparando-se as médias de condutividade hidráulica, observa-se diminuição destas com o aumento das doses de bentonita devido, provavelmente, ao aumento do teor de argila nas amostras de terra (Loureiro et al. 1990) e/ou ao aumento no teor de argila dispersa no meio; entretanto, não foi observada diferença significativa entre a lestemunha e a dose de $30 \mathrm{t}$ ha ${ }^{1}$ nem entre as doses de 60 e $90 \mathrm{t} \mathrm{ha}^{-1}$. Como o regossolo é muito permeável, numa primeira assertiva pode-se dizer que o eleito da incorporação da bentonita foi satisfatório, pois o fato da condutividade hidráulica haver diminuído implica em dizer que a água permanecerá por mais tempo no solo, à disposição das plantas.

Tabela 3. Efeito de diferentes níveis de bentonila sobre o conteúdo de água disponível, condutividade hidráulica e argila dispersa em água, nas amostras de lerra, após a incubação

\begin{tabular}{cccc}
\hline $\begin{array}{c}\text { Doses de bentonita } \\
\mathrm{t} \mathrm{ha}^{-1}\end{array}$ & $\begin{array}{c}\text { Água Disponível } \\
\mathrm{m}^{3} \mathrm{~m}^{-3}\end{array}$ & $\begin{array}{c}\text { Condutividade Hidráulica } \\
\mathrm{m} \mathrm{s}^{-1}\end{array}$ & $\begin{array}{c}\text { Argila Dispersa } \\
\mathrm{g} \mathrm{kg}^{-1}\end{array}$ \\
\hline 0 & $0,061 \mathrm{~b}$ & $0,25 \mathrm{a}$ & $1,42 \mathrm{bc}$ \\
30 & $0,136 \mathrm{a}$ & $0,18 \mathrm{ab}$ & $1,32 \mathrm{c}$ \\
60 & $0,151 \mathrm{a}$ & $0,15 \mathrm{~b}$ & $1,45 \mathrm{ab}$ \\
90 & $0,1574 \mathrm{a}$ & $0,12 \mathrm{~b}$ & $1,56 \mathrm{a}$ \\
\hline
\end{tabular}

Médias seguidas da mesma letra nas colunas, não diferem estatisticamente entre si pelo teste de Tukey a $5 \%$ de probabilidade

\section{CONCLUSÕES}

A aplicação de bentonita aumentou a água disponível do solo e reduziu a capacidade do solo para transmitir água. Como ambos os fenômenos favorecem a permanência da água no solo, poderiam ser recomendados como condicionador para um solo permeável como o regossolo.

\section{REFERÊNCIAS BIBLIOGRÁFICAS}

CHOUDHURY, E.N. \& FARIA, C.M.B.. Inlluência da vermiculita sobre a produção de melão e intervalo de irrigação no trópico semi-árido do Nordeste. Boletim de pesquisa, Petrolina, PE: EMBRAPA-CPATSA. v.18, 20p, 1982.

EMBRAPA. Serviço Nacional de Levantamento e Conservação do solo. Manual e métodos de análise de conservação de solo. Rio de Janeiro: EMBRAPA-SNLCS, 1979.

FORTES, J.L.O. \& CAMPOS NETO, D.. Alterações nas características químicas do solo e produção vegetal do milho com uso de resíduos de bauxila e cinza de caldeira. In: XXV CONGRESSO BRASILEIRO DE CIÊNCIA DO SOLO, III, 1995, Viçosa. Resumos, Sociedade brasileira de Ciência do Solo, 1995. p.1331-1333.

LOGAN, T.J. \& PREZOTO, M.E.M.. Avaliação da possibilidade de uso agronômico de lodo de esgoto tratado com resíduo de indústria de cimento. In: XX REUNIÃO BRASILEIRA DE FERTILIDADE DO SOLO E NUTRIÇÃO DE PLANTAS. Piracicaba, 1992. Anais., Sociedade Brasileira de ciência do Solo, 1992. p.386-387.

LOUREIRO, B.T., GALDINO, S., FERREIRA, P.A., OLIVEIRA, L.M. Estimativa da macroporosidade baseada em algumas caraclerísticas de solo de varzea. Revista Ceres, v.37, n. 211, p. 190-214. 1990.

MESSIAS, A.S. \& MORAIS, F.A. Emprego do lixo urbano na adubação do milheto. In: XX REUNIÃO BRASILEIRA DE FERTILIDADE DO SOLO E NUTRIÇÃO DE PLANTAS, Piracicaba. 1992. Anais. Campinas, Sociedade Brasileira de Ciência do Solo, 1992. p.384 385.

NOVELINO, J.O. ; LEITE, P.C. ; PROENÇA, S.S. \& SILVA, M.L.. Características químicas de dois latossolos de Dourados, MS, submetidos à aplicação de pó de basalto. In: XXV CONGRESSO BRASILEIRO DE CIÊNCIA DO SOLO, III, 1995 Viçosa. Resumos, Sociedade Brasileira de Ciência do solo, !995. p.1334-1335.

REEVE, R.C. The measurement of permeability in the laboratory. Agron. 7:414-419. 1957.

RICHARDS, L. A. Porrous plate apparatus for measuring moisture retention and transmission by soil. Soil Sci. 66:105110. 1948.

ROS, C.O. ; AITA, C. ; CERETTA, C.A. \& FRIES, M.R. Lodo de esgoto: efeito imediato no milheto e residual na associação aveia-ervilha. Rev. bras. Ci. Solo, Campinas, v.17, n.2, p. 257 261, 1993.

SALATI, E., REICHARDT, K. \& UQUIAGA, C.S. Efeito da adição da vermiculita na relenção e armazenamento de água por latossolos. Rev. bras. Ci. Solo, Campinas, v.4, p.125$131,1980$.

SANTOS, P.S. Tecnologia de argilas. São Paulo: Edgar Blucher, v.I, 1975. 340p.

SANTOS, P.S. Estudo tecnológico da argila montmorilonítica do Distrito de Boa Vista, município de Campina Grande, Paraíba. Instituto de pesquisa tecnológica do Estado de São Paulo. Publicação $\mathrm{N}^{0}: 862$. 1976. 53p.

SOUZA, C.M., FIGUEIREDO, M.S., COSTA, L.M. \& GALVÃO, J.C.C. Uso do lodo primário da indústria de celulose e papel em povoamentos de eucalipto. In: XXII REUNIĀO BRASILEIRA DE FERTILIDADE DO SOLO E NUTRIÇÃO DE PLANTAS, Manaus, 1996. Resumo. , Sociedade Brasileira de Ciência do Solo, 1996. p.537-538. 